Open Access

\title{
Bcl-2 Over-Expression and Genetic Manipulation of T Cells Provides Tumor Specificity and Enhanced Resistance to Apoptosis In Vitro
}

\author{
Hollie J. Pegram, Phillip K. Darcy ${ }^{\#}$ and Michael H. Kershaw,**
}

Cancer Immunotherapy Research Laboratory, Peter MacCallum Cancer Centre, Melbourne, Australia

\begin{abstract}
Adoptive immunotherapy using T cells has produced some encouraging clinical responses, but deficiencies resulting from a frequent lack of tumor specificity and poor survival of these cells has limited the widespread application of this approach. We used a chimeric receptor gene specific for erbB2 in T cells with genetic resistance to apoptosis to address these deficiencies. Expression of the chimeric receptor was found to be equivalent in $\mathrm{T}$ cells from $b c l-2$ transgenic-, lpr- and wild-type C57BL/6 mice. Furthermore, T cells from each mouse strain secreted similar amounts of IFN- $\gamma$ in response to erbB2, and lysed erbB2 ${ }^{+}$tumor cells to a similar degree. Interestingly, we demonstrated that erbB2-specific T cells from Bcl-2 transgenic mice have enhanced expansion in vitro compared to $\mathrm{T}$ cells from C57BL/6 and Lpr mice. In addition, transduced T cells from Bcl-2 transgenic mice demonstrated increased resistance to apoptosis following activation or cytokine withdrawal, when compared to Lpr and BL/6 cells.
\end{abstract}

\section{INTRODUCTION}

The immune response to cancer is often compromised due to features of tumor biology, such as their expression of self-antigens that are largely ignored by the immune system, resulting in a paucity of tumor-specific $\mathrm{T}$ cells. In addition, tumor cells often down regulate or lose expression of MHC/peptide complexes and/or important co-stimulatory ligands from their cell surface [1], and express immune inhibitory cytokines [2]. Thus, tumor-specific $\mathrm{T}$ cells are often lacking in the tumor host or $\mathrm{T}$ cell interaction with tumor frequently results in anergy or suppression rather than activation to effector or memory status. These problems can preclude success with current immunotherapies involving active immunization strategies and adoptive $\mathrm{T}$ cell transfer.

The provision of tumor specificity has been addressed using a genetic engineering strategy. This approach has involved modifying $\mathrm{T}$ cells with a chimeric single-chain $(\mathrm{scFv})$ gene construct encoding a receptor that specifically recognizes the erbB2 tumor associated antigen [3]. This antierbB2-CD28- $\zeta$ receptor provides tumor specificity to the $\mathrm{T}$ cell and contains an intracellular co-stimulatory signaling component (CD28) linked in tandem to the CD3- $\zeta$ chain, which has been shown to activate $\mathrm{T}$ cells. In addition, encouraging results have been obtained using $T$ cells modified with this chimeric gene construct in adoptive transfer studies in animal models [4-7]. A range of other chimeric scFv T-bodies have also been developed targeting a wide variety of tumor-associated antigens (TAA) including erbB2 [8], folate-binding protein (FBP) [7], CD19 [9, 10], prostate-specific membrane antigen (PSMA) [11], IL-13

\footnotetext{
*Address correspondence to this author at the Peter MacCallum Cancer Centre, 14 St. Andrews Place, East Melbourne, Victoria, Australia, 3002; Tel: +613 96561177; Fax: +613 96561411; E-mail: michael.kershaw@petermac.org

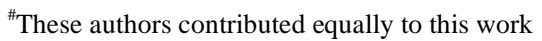

receptor [12], carcinoembryonic antigen (CEA) [13] and Lewis-Y [14]. These antigens are expressed on a range of malignancies including lymphoma, glioblastoma and carcinomas of the breast, ovary, prostate and colon.

Nevertheless, anti-tumor effects in mice using $\mathrm{T}$ cells expressing these receptors are generally observed against only disseminated or small tumors and early stage disease but have had minimal impact on larger tumors $(>5 \mathrm{~mm})$ and against established metastatic disease [3]. A significant problem that has become evident from these studies relates to the survival of transferred lymphocytes, particularly in immunocompetent mice. Adoptively transferred lymphocytes do not persist in significant numbers past 3 days and disappear by three weeks [7]. This problem with persistence is also evident in patients undergoing adoptive transfer of tumor infiltrating lymphocytes (TIL) for the treatment of melanoma. Improved clinical responses have correlated with persistence of adoptively transferred $\mathrm{T}$ cells in patients [15-18], although pre-conditioning of patients to increase persistence is associated with an increased risk of infection.

Thus, the aim of this study was to determine whether we could harness the molecular control of $\mathrm{T}$ cell fate, in particular contraction of the immune response, for better immunotherapy of cancer. Reasoning that the enhanced persistence of transferred $\mathrm{T}$ cells would lead to improved anti-tumor effects, we hypothesized that tumor-specific $\mathrm{T}$ cells with lower sensitivity to apoptosis would demonstrate enhanced persistence leading to an increased opportunity to exert anti-tumor effects. In order to test this, T cells from mice with altered death pathways were used, namely, the vav.bcl-2 (Bcl-2) and mrl.lpr (Lpr) strains of mice, both on a C57BL/6 background. The Lpr mouse has a mutation resulting in the lack of expression of death receptor Fas [19], and the Bcl-2 mouse over expresses the anti-apoptotic molecule, Bcl-2 [20].

This study determined whether the expansion and/ or lifespan of tumor-specific $\mathrm{T}$ cells could be increased 
without impairing lymphocyte function (cytolytic and cytokine secretion ability), which may eventually lead to the improvement of adoptive $\mathrm{T}$ cell transfer immunotherapies for cancer.

\section{MATERIALS AND METHODS}

\section{Cell Culture}

The murine ecotropic retroviral producing cell line GP+E86 harboring the chimeric single chain anti-erbB2 receptor (anti-erbB2-CD28- $\zeta$ ) used in this study was generated as previously described [3]. The murine C57BL/6 melanoma cell line B16-F10 was from the American Type Culture Collection (ATCC, Manassas, VA, USA), and its erbB2 transfectant, B16-F10-erbB2, was generated by transduction with the retroviral vector MSCV containing the cDNA encoding human erbB2. Tumor cell lines and retroviral packaging cell lines were maintained at $37^{\circ} \mathrm{C}$ and $10 \% \mathrm{CO}_{2}$ in DMEM supplemented with $10 \%(\mathrm{v} / \mathrm{v})$ heat inactivated fetal calf serum (FCS) (Thermoelectron, Noble Park, VIC, Australia), $100 \mathrm{U} / \mathrm{ml}$ penicillin (Sigma, Castle Hill, NSW, Australia) and $100 \mu \mathrm{g} / \mathrm{ml}$ streptomycin (Sigma) and $2 \mathrm{mM}$ L-glutamine (JRH Biosciences, Brooklyn, VIC, Australia). Mouse T cells were cultured in RPMI 1640 medium (Gibco, Grand Island, NY, USA), supplemented with $10 \%$ (v/v) FCS (Thermoelectron), $2 \mathrm{mM}$ L-Glutamine (JRH Biosciences), $0.1 \mathrm{mM}$ non-essential amino acids (Gibco), $1 \mathrm{mM}$ sodium pyruvate (Gibco), $5 \times 10^{-2} \mathrm{mM} 2 \mathrm{ME}$ (Sigma), $100 \mathrm{U} / \mathrm{ml}$ penicillin and 100 $\mu \mathrm{g} / \mathrm{ml}$ streptomycin (Sigma), and $50 \mathrm{IU} / \mathrm{ml}$ human recombinant interleukin-2 (IL-2) [National Cancer Institute (NCI), Frederick, MD, USA].

\section{Mice}

Inbred C57BL/6 (BL/6) and BL/6.mrl.lpr (Lpr) mice were purchased from The Walter and Eliza Hall Institute of Medical Research (WEHI), (Parkville, Australia). BL/ 6.vav.Bcl-2 (Bcl-2) mice were provided by Dr Jerry Adams and Dr Phillipe Bouillet (WEHI) and all mice were housed in specific pathogen free conditions at the Peter MacCallum Cancer Centre (PMCC). Mice of 4-12 weeks of age were used in all experiments that were performed in accordance with PMCC animal experimental ethics committee guidelines.

\section{T Cell Isolation and Generation of erbB2-Specific T Cells}

Coculture of nylon wool-enriched mouse splenic $\mathrm{T}$ cells with the GP+E86 ecotropic packaging cell line expressing the anti-erbB2-CD28- $\zeta$ receptor was used to generate erbB2specific $\mathrm{T}$ cells as described previously [3]. Following co-culture, $\mathrm{T}$ cells were then separated from the adherent packaging cells, washed twice and cultured in RPMI supplemented media with IL-2, plus G418 $(0.5 \mathrm{mg} / \mathrm{ml})$ (Invitrogen). The addition of G418 for 6 days enabled the enrichment of transduced $\mathrm{T}$ cells by the neomycin resistance gene included in the pLXSN vector (Fig. 1).

\section{Flow Cytometry}

The expression of the chimeric receptor on the surface of transduced $\mathrm{T}$ cells from BL/6, Bcl-2 and Lpr mice was determined by indirect immunofluorescence with a primary anti-c-myc tag monoclonal antibody (anti-tag) (clone number 9B11, Cell Signaling Technology, Beverly, MA, USA) followed by a secondary antibody: a PE-conjugated antimouse immunoglobulin (Chemicon, Melbourne, VIC, Australia). The determination of background fluorescence was achieved by staining with the PE conjugated anti-mouse immunoglobulin alone. Transduced $\mathrm{T}$ cells (approximately $2 \times 10^{6}$ cells) were incubated with $20 \mu \mathrm{l}$ of the appropriately diluted antibody at $4^{\circ} \mathrm{C}$ for $30 \mathrm{~min}$, washed twice in buffer, consisting of phosphate buffered saline (PBS) with 0.5\% $(\mathrm{w} / \mathrm{v})$ bovine serum albumin (BSA) (JRH Biosciences) and the fluorescence of equal numbers of viable cells was analyzed using a FACSCalibur flow cytometer (Becton Dickinson). Experiments were repeated four times.

\section{Cytotoxicity Assay}

The ability of BL/6, Bcl-2 and Lpr T cells expressing the chimeric receptor to specifically kill tumor targets was assessed by incubating T cells, 7 days post-stimulation, with ${ }^{51} \mathrm{Cr}$-labeled target cells (in $200 \mu \mathrm{L}$ of supplemented RPMI) at different effector to target (E:T) ratios in triplicate wells of a 96-well round bottomed cell culture plate, and incubated for $4 \mathrm{hrs}$ at $37^{\circ} \mathrm{C}$ and $5 \% \mathrm{CO}_{2}$. Spontaneous release of ${ }^{51} \mathrm{Cr}$ was determined by incubating the target cells in supplemented RPMI alone, and maximal release was determined by adding SDS (Sodium dodecyl sulfate) (Sigma) to target cells, at a final concentration of $10 \%(\mathrm{v} / \mathrm{v})$. Following incubation, cells were spun at $1500 \mathrm{rpm}(451 \mathrm{~g})$ for $5 \mathrm{~min}$ and the radioactivity of the supernatant was measured by a Wallace 1470 automatic gamma-counter (Walla, Finland). All experiments were performed twice for triplicate samples, and cytotoxicity was expressed as the percentage specific ${ }^{51} \mathrm{Cr}$ release after subtraction of spontaneous ${ }^{51} \mathrm{Cr}$ release.

\section{Cytokine Production Assay}

IFN- $\gamma$ secretion by transduced BL/6, Bcl-2 and Lpr T cells, 7 days post-stimulation, was measured using enzyme linked immunosorbent assay (ELISA) following receptor ligation. Co-cultures of $1 \times 10^{6}$ tumor targets (B16-F10 or B16-F10-erbB2) with $2 \times 10^{6} \mathrm{~T}$ effector Lymphocytes (transduced BL/6, Bcl-2 or Lpr mouse $\mathrm{T}$ cells) in a final

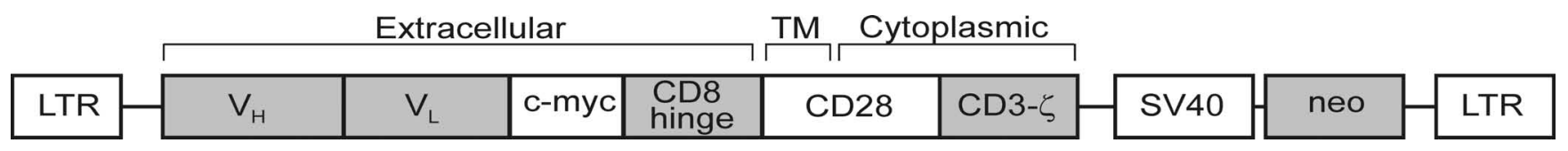

Fig. (1). Schematic representation of the retroviral vector, derived from LXSN, used to genetically modify $T$ cells. The chimeric receptor is composed of the $\mathrm{V}_{\mathrm{H}}$ and $\mathrm{V}_{\mathrm{L}}$ domains of a monoclonal antibody specific for human erbB2, which is linked via a c-myc epitope to the human CD8 hinge region, the mouse CD28 region and the cytoplasmic domain of human CD3- $\zeta$. Expression of the chimeric receptor is driven by the Moloney murine leukemia virus long terminal repeat (LTR). An antibiotic selectable marker, neo, is also included in the vector driven by the SV40 promoter. Extracellular, transmembrane (TM) and cytoplasmic regions as listed. 
volume of $1 \mathrm{ml}$ RPMI supplemented media were used. After overnight culture, supernatants were harvested and analyzed using specific antibodies and ELISA as described previously [3].

\section{Cell Counts}

Equivalent numbers $\left(1 \times 10^{7}\right.$ cells $)$ of transduced T cells derived from BL/6, Bcl-2 and Lpr mice were seeded into the wells of 24-well plates at $1 \times 10^{6}$ cells $/ \mathrm{ml}$ and cell counts performed periodically for 19 days after G418 selection. Total cell number was determined by resuspending 3 wells of $\mathrm{T}$ cell culture and pooling $50 \mu \mathrm{l}$ from each well and counting this pool twice. Cell numbers represent viable cells, as determined by counting the cells in Trypan blue, and this experiment was repeated three times.

\section{Apoptosis Assay}

Survival of transduced BL/6, Bcl-2 and $\mathrm{Lpr}$ mouse $\mathrm{T}$ cells following receptor ligation was assessed by Annexin V staining. Transduced BL/6, Bcl-2 and Lpr T cells expressing the anti-erbB2-CD28- $\zeta$ receptor were cultured at $1 \times 10^{5} / 200$ $\mu \mathrm{l}$, in 96-well tissue culture plates with either immobilized anti-tag antibody, IL-2 $(60 \mathrm{U} / \mathrm{ml})$ or $1 \mu \mathrm{M}$ staurosporine (STS) (Sigma), or in the absence of IL-2. At 8, 24 and $48 \mathrm{hrs}$ cells were harvested and stained with PI and Annexin-V conjugated to FITC (BD Pharmingen) in Annexin-V buffer containing $40 \mathrm{mM}$ Hepes (JRH), $600 \mathrm{mM} \mathrm{NaCl}, 20 \mathrm{mM}$ $\mathrm{KCl}, 4 \mathrm{mM} \mathrm{MgCl}$, and $7.2 \mathrm{mM} \mathrm{CaCl}$. Fluorescence intensity of equal numbers cells was then analyzed by FACSCalibur flow cytometer (Becton and Dickinson). This experiment was repeated three times.

\section{Statistical Analysis}

Statistical significance in experiments was determined using the Mann-Whitney U-test, a non-parametric test for the comparison of independent samples. Results given, are a two-sided $\mathrm{P}$ value $(\mathrm{P} 2)$, representing the probability that the observation occurred by chance alone. The observed difference between groups was considered significant when the $\mathrm{P} 2$ value was less than or equal to 0.05 .

\section{RESULTS}

Comparable Expression of the scFv Anti-erbB2 Chimeric Receptor in Mouse T Cells from BL/6, Bcl-2 and Lpr Mice

We first wished to determine if tumor-specific $\mathrm{T}$ cells, with anti-tumor function equivalent to wild type BL/6 mice, could be generated from Bcl-2 and Lpr mice. The first step in answering this question was to determine whether $\mathrm{T}$ cells from Bcl-2 and Lpr mice could be transduced to a similar level as T cells from BL/6 mice.

For this experiment, enriched mouse $\mathrm{T}$ cells from each of the strains of mice were transduced with the anti-erbB2-CD28- $\zeta$ receptor by co-culture with retroviral vector-producing cells. Expression was assessed by flow cytometry following staining with an anti-c-myc (anti-tag) antibody. This antibody binds to the c-myc epitope incorporated into the extracellular domain of the receptor construct (Fig. 1). Transduced $\mathrm{T}$ cells from $\mathrm{Bcl}-2$ and $\mathrm{Lpr}$ mice reproducibly expressed levels of chimeric $\mathrm{scFv}$ receptor on the cell surface similar to wild type BL/6 mice, with approximately $45-55 \%$ of $\mathrm{T}$ lymphocytes staining positive for anti-tag (Figs. 2a-c). The specificity of staining was apparent by the lack of staining using secondary antibody alone and the failure of the anti-tag antibody to stain control non-transduced wild-type C57BL/6 T cells (Fig. 2d).
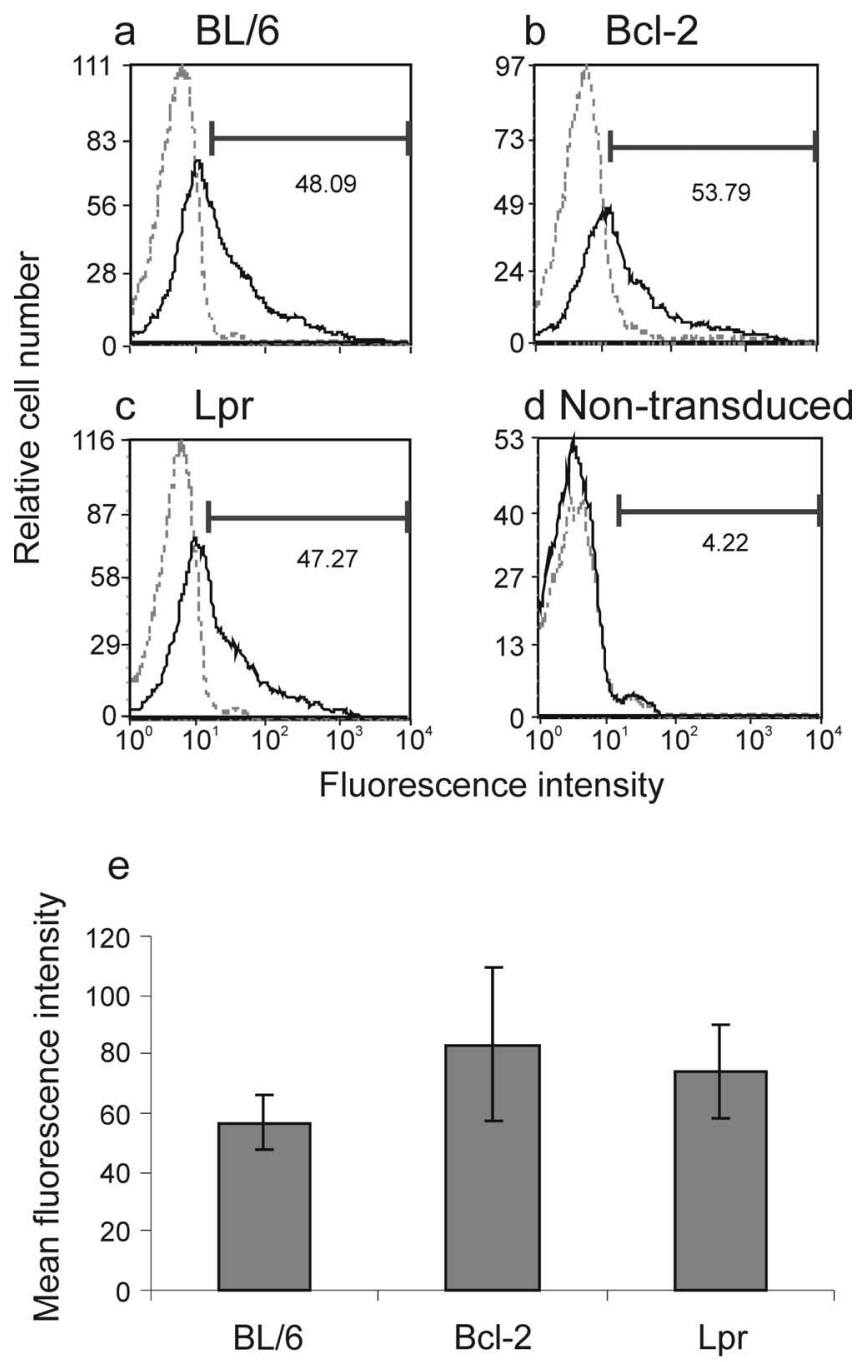

Fig. (2). T cells derived from BL/6, BL/6-Bcl-2 and BL/6-Lpr mice express similar levels of chimeric receptor. $T$ cells from wildtype BL/6 mice (a) or Bcl-2 transgenics (b) or Lpr mice (c) were transduced and analyzed using flow cytometry following staining with an anti-tag antibody and secondary PE-conjugated anti-mouse immunoglobulin (solid line), or secondary antibody alone (broken line). Non-transduced BL/6 T cells serve as a negative control for receptor expression (d). Percentages of positive cells in the marked region are listed. The mean fluorescence intensity (MFI) data from four flow cytometric experiments comparing chimeric receptor expression in the 3 mouse strains is presented in panel (e). There was no statistical difference in MFI between transduced $\mathrm{T}$ cells from either mouse strain. ( $\mathrm{P} 2=0.34$ for BL/6 vs Bcl2 and $\mathrm{P} 2=0.89$ for BL/6 vs Lpr).

In a series of four independent experiments, the mean fluorescence intensity (MFI) of anti-tag staining of $\mathrm{T}$ cells was not significantly different between $\mathrm{T}$ cells from BL/6, 
Bcl-2 and Lpr mice (Fig. 2e) indicating that transduction efficiency was not affected by the genotypic background of mice. Therefore, BL/6- Bcl-2- and Lpr-derived T cells expressed equivalent levels of chimeric receptor on their surface, suggesting their capacity to respond against tumor cells would be similar.

Transduced $T$ Cells from BL/6, Bcl-2 and Lpr Mice Exhibit Similar Ability to Secrete Cytokines

Prior to determining whether transduced $\mathrm{T}$ cells from Bcl-2 or Lpr mice could exhibit improved survival it was important to investigate whether other $\mathrm{T}$ cell functions were compromised in these mice compared with transduced $\mathrm{T}$ cells from BL/6 mice. Cytokines form an important part of the $\mathrm{T}$ cell response, resulting in amongst other responses, activation and cellular recruitment.

Interferons are important for sensitizing other cells in the immune system and communication with the innate immune system. To investigate this function, we first assessed the ability of the transduced T cells from BL/6, Bcl-2 and Lpr mice to secrete IFN- $\gamma$ after overnight culture with erbB2 ${ }^{+}$ (B16F10-erbB2) and parental tumor (B16F10), to allow determination of activation specifically in response to tumor antigen. Following co-culture, supernatants were harvested and secretion of IFN- $\gamma$ determined using ELISA.

Transduced $\mathrm{T}$ cells from all three strains of mice were able to significantly secrete more IFN $-\gamma$ in response to B16F10-erbB2 tumor cells compared to stimulation with parental B16F10 cells (Fig. 3). The level of IFN- $\gamma$ secreted following stimulation with B16F10-erbB2 was not significantly different between transduced $\mathrm{T}$ cells from $\mathrm{BL} / 6$, Bcl-2 or Lpr mice indicating they were capable of mounting a similar response against tumor cells.

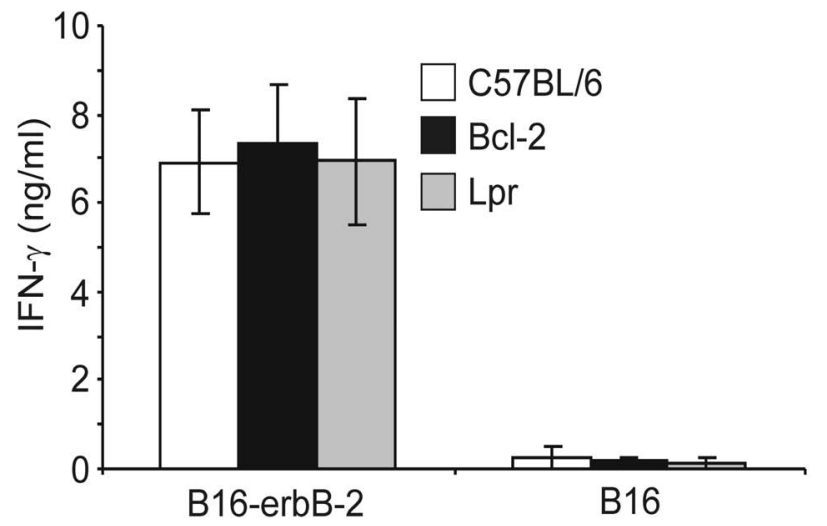

Fig. (3). Transduced BL/6, Bcl-2 and $\mathrm{Lpr} T$ cells secrete equivalent levels of IFN- $\gamma$ in response to $\operatorname{erbB2}^{+}$tumor cells. $\mathrm{T}$ cells were incubated overnight with erbB2 ${ }^{+} \mathrm{B} 16$ cells or erbB2 B16 cells. Supernatants were harvested and ELISA used to determine the amount of IFN- $\gamma$ secreted. Results are representative of 5 experiments. There were no significant differences in IFN- $\gamma$ secretion from either mouse strain ( $\mathrm{P} 2 \geq 0.604)$.

Transduced T Cells from BL/6, Bcl-2 and Lpr Mice Exhibit Similar Ability to Specifically Lyse Tumor Targets

An important function of $\mathrm{T}$ cells is their lytic capability. Cytotoxic $\mathrm{T}$ cells (CTL) kill targets by releasing granules containing perforin and granzymes, or alternatively engaging death receptors such as Fas. We therefore tested the ability of transduced $\mathrm{T}$ cells from BL/6, Bcl-2 and Lpr mice to specifically lyse erbB2 $2^{+}$tumor targets in a standard $4 \mathrm{hr}{ }^{51} \mathrm{Cr}$ assay, which investigates granule mediated killing, involving perforin and granzymes.

Transduced $\mathrm{T}$ cells from all three strains of mice could effectively lyse B16F10-erbB2 tumor cells (Fig. 4). Lysis was erbB2 $2^{+}$specific since transduced $\mathrm{T}$ cells did not kill parental B16F10 tumor cells. The percentage specific lysis of B16F10-erbB2 cells was similar for transduced BL/6, Bcl-2 and Lpr T cells.
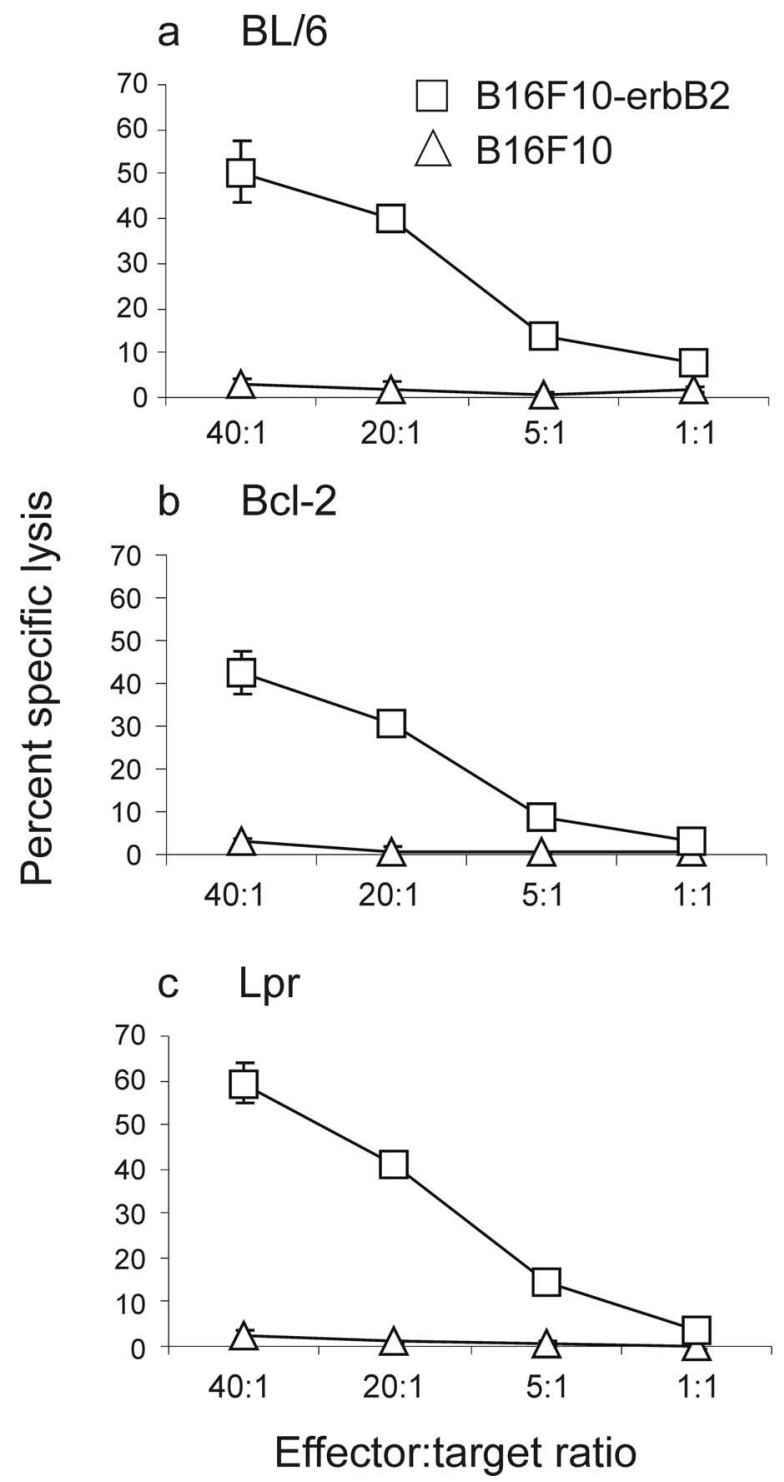

Fig. (4). Transduced T cells from BL/6, Bcl-2 and Lpr mice lyse tumor cells to a similar degree. Mouse $\mathrm{T}$ cells from the listed strains were incubated with ${ }^{51} \mathrm{Cr}$-labeled B16-erbB2 ${ }^{+}$cells (squares) or B16 parental cells (triangles) and the percent specific lysis determined at the listed effector:target ratios. The results are the average lysis \pm SEM of triplicate samples from 3 independent experiments. No statistically significant difference for lysis of B16erbB2 ${ }^{+}$cells was observed (at 40:1 E:T ratio) between transduced $\mathrm{BL} / 6$ and transduced Bcl-2 or Lpr T cells (P2 > 0.05 as determined by a Mann-Whitney test). 
Enhanced Expansion of Transduced T Cells from Bcl-2 Transgenic Mice

Collectively, our results above demonstrated that cytokine release and lytic ability was not altered in transduced T cells from Bcl-2 and Lpr mice when compared to BL/6-derived transduced $\mathrm{T}$ cells. One of the limitations of adoptive transfer immunotherapy has been the poor ability of the transferred $\mathrm{T}$ cells to survive and persist in the host after adoptive transfer. Therefore, we next investigated the ability of transduced $\mathrm{T}$ cells from Bcl-2 and Lpr mice to survive and expand in culture compared with transduced $\mathrm{T}$ cells from BL/6 mice. Following transduction, $\mathrm{T}$ cells from all strains of mice were cultured at $1-2 \times 10^{6}$ cells $/ \mathrm{ml}$ with $50 \mathrm{IU} / \mathrm{ml}$ IL-2 and live cells counted by trypan blue staining at various time points. Interestingly, from a number of independent experiments, transduced $\mathrm{T}$ cells from $\mathrm{Bcl}-2$ mice demonstrated a reproducible increase in expansion as assessed by total cell number compared with transduced $\mathrm{T}$ cells from either BL/6 or Lpr mice (Fig. 5).

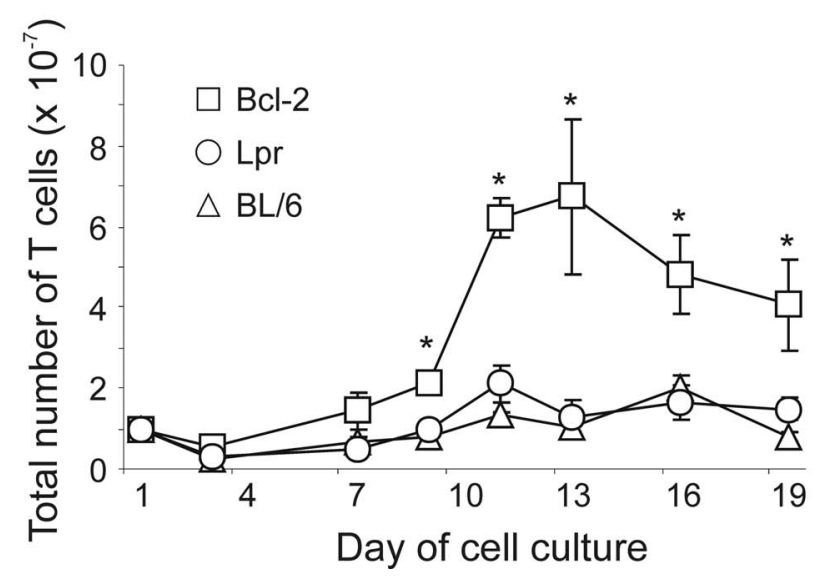

Fig. (5). Enhanced expansion of transduced $\mathrm{T}$ cells from Bcl-2 transgenic mice. Cultures of $1 \times 10^{7}$ transduced $\mathrm{T}$ cells from BL/6, Bcl-2 and Lpr mice were initiated on Day 1. The number of viable cells was determined periodically over 19 days using a hemocytometer and trypan blue exclusion. Data is the average of three experiments using triplicate wells in each experiment \pm SEM. Expansion of transduced $\mathrm{T}$ cells from Bcl-2 mice was significantly greater compared to transduced BL/6 and Lpr T cells $(* \mathrm{P} 2<0.05$, Mann-Whitney test).

Enhanced Expansion of Transduced $T$ Cells from Bcl-2 Mice May be Due to an Increased Resistance to Apoptosis

We next investigated whether transduced $\mathrm{T}$ cells from Bcl-2 or Lpr mice had a reduced tendency to undergo apoptosis, particularly after encountering chimeric receptor ligation. To investigate this, $\mathrm{T}$ cells were placed in culture under various stimulation conditions and, at selected time points, were collected and stained with FITC-conjugated Annexin V and propidium iodide (PI). Early in apoptosis phospholipid phosphotidylserine translocates to the outer membrane where Annexin V can bind, and PI is a DNAintercalating agent that is excluded from live cells. Thus, these two reagents are commonly used to detect apoptotic and non-viable cells. The percentage surviving cells was determined on the basis of both Annexin V and PI negative gated cells. Given that staurosporine (STS) is a known apoptotic stimulus that inhibits protein kinases and induces apoptosis by the Bcl-2 mediated apoptosis pathways, it was included in these experiments as a control.

Although transduced $\mathrm{T}$ cells from all three strains of mice showed similar levels of apoptosis in the presence of IL-2 (Fig. 6a), a greater percentage of surviving cells was observed from Bcl-2 mice under conditions of IL-2 withdrawal and anti-tag stimulation (Figs. 6b-c). Importantly, these are the conditions that a transferred lymphocyte could encounter in vivo, and suggests that transduced $\mathrm{T}$ cells over expressing the Bcl-2 molecule may have greater opportunity to exert anti-tumor effects as they have the capacity to survive better after antigen encounter. Transduced T cells from Bcl-2 mice clearly demonstrated a greater percentage of surviving cells in the presence of STS which induced apoptosis in transduced $\mathrm{T}$ cells from BL/6 and Lpr mice (Fig. 6d), confirming that $\mathrm{Bcl}-2$ over expression protects cells from apoptosis through the mitochondrial pathway.

\section{DISCUSSION}

Immunotherapy is a potent method to harness and complement the natural power and specificity of the immune system. Current immunotherapeutic strategies involving the adoptive transfer of $\mathrm{T}$ cells have been very encouraging, in particular for the treatment of melanoma [15, 21-23]. There are however, limitations concerning the low levels of persistence and survival of transferred $\mathrm{T}$ cells in the patient. Improved clinical responses are associated with long-term persistence of adoptively transferred $\mathrm{T}$ cells [15-18]. However, the method of enhancing persistence of $\mathrm{T}$ cells in these cases involves various degrees of prior immune conditioning using cyclophosphamide, fludarabine and irradiation, which results in profound myelo-depletion and greatly increased risk of infection. The current study investigates other potential means of enhancing $\mathrm{T}$ cell persistence not requiring myelo-suppression.

Two potential strategies to increase the survival and persistence of adoptively transferred $\mathrm{T}$ cells include the over expression of a pro-survival molecule, represented here by the BL/6.vav.Bcl-2 mouse which over expresses the Bcl-2 molecule in the hematopoietic system; or downregulating expression of molecules in the death receptor mediated apoptosis pathway, represented in this study by the Fas mutation that the BL/6.mrl.Lpr mouse possesses.

Our first task was to demonstrate that $\mathrm{T}$ cells from these strains of mice could be transduced with the anti-erbB2 chimeric receptor similarly to wild-type BL/6 mice. In this study, transduced $\mathrm{T}$ cells from all three strains of mice expressed equivalent amounts of the chimeric $\mathrm{scFv}$ receptor.

An important component of this study was to demonstrate that $\mathrm{T}$ cell effector function was not compromised in $\mathrm{T}$ cells from Bcl-2 and Lpr mice, as enhanced persistence must not come at the cost of $\mathrm{T}$ cell function. This was assessed by measuring antigen-specific release of cytokine and cytolytic ability of transduced T cells. In this study, equivalent levels 


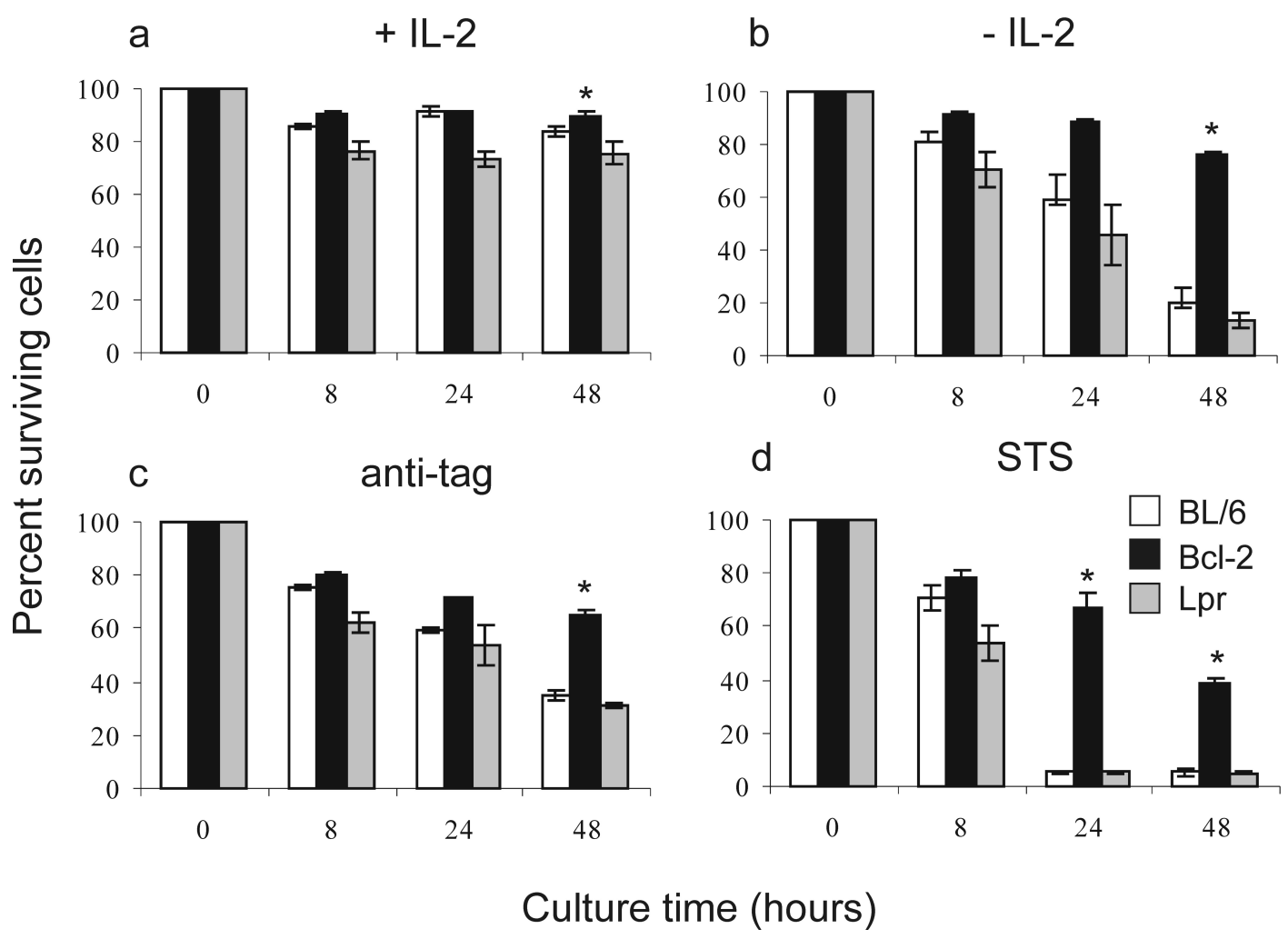

Fig. (6). Transduced Bcl-2 T cells demonstrated greater survival following stimulation, compared to transduced BL/6 and Lpr T cells. Transduced BL/6, Bcl-2 and Lpr T cells were cultured at $5 \times 10^{5}$ cells/ml, with IL-2 (a), without IL-2 (b) with plate-bound anti-tag antibody or with staurosporine (STS) (c,d). Cells were harvested at the designated time points and stained with Annexin V and propidium iodide (PI) and fluorescence analyzed using flow cytometry. Annexin $\mathrm{V}^{-} \mathrm{PI}^{-}$cells represented surviving cells in these assays, relative to the 0 hr timepoint. Data represents average percentage surviving cells \pm SEM of duplicate wells from 3 independent experiments. * denotes statistically significant differences between transduced Bcl-2 T cells and transduced $\mathrm{T}$ cells form both BL/6 and Lpr mice. (*P2 < 0.05, MannWhitney test).

of IFN- $\gamma$ were secreted by transduced T cells from all three strains of mice following antigen-specific stimulation. This was important since it has been previously shown that cytokines, particularly IFN- $\gamma$, are critical for anti-tumor function of gene-engineered $\mathrm{T}$ cells [3]. Furthermore, transduced $\mathrm{T}$ cells from BL/6, Bcl-2 and Lpr mice demonstrated similar ability to lyse erbB2 ${ }^{+}$tumor targets. Thus the results clearly indicated that effector function, in terms of cytokine release and lytic ability was not reduced in transduced $\mathrm{T}$ cells from either $\mathrm{Bcl}-2$ or $\mathrm{Lpr}$ mice. This supports the feasibility of this strategy for adoptive immunotherapy, as increased expansion did not come at the cost of $\mathrm{T}$ cell phenotype or function.

Given that receptor expression and effector function was not compromised in $\mathrm{T}$ cells from $\mathrm{Bcl}-2$ and $\mathrm{Lpr}$ mice, we next investigated whether these $\mathrm{T}$ cells could exhibit improved survival. Interestingly, only transduced $\mathrm{T}$ cells from Bcl-2 mice demonstrated enhanced expansion in culture compared with $\mathrm{T}$ cells from either Lpr or wild type BL/6 mice. Bcl-2 transgenic T cells did eventually decrease in number after approximately two weeks (Fig. 5) and this contraction may have been due to Bcl-2-independent death, which has been described before [24, 25].

We found, in a number of experiments measuring cell death, that following receptor stimulation or withdrawal of the $\mathrm{T}$ cell growth factor, IL-2, Bcl-2 derived transduced $\mathrm{T}$ cells had a survival advantage over Lpr and BL/6 derived transduced $\mathrm{T}$ cells. This is an important finding, as survival after stimulation is a feature that would be required for treatment of a recurring cancer i.e. the lymphocytes need to persist after initial tumor clearance to fight recurring malignancies. It is also reported that tumor microenvironments have low levels of IL-2 [26], thus endowing lymphocytes with the ability to survive in the absence of IL- 2 would theoretically result in greater anti-tumor efficacy. However, it is not clear from these studies whether $\mathrm{T}$ cells surviving IL-2 withdrawal would possess equivalent anti-tumor response capabilities as IL-2-cultured $\mathrm{T}$ cells. It would be interesting to investigate this in future studies. In addition, the difference in sensitivity of Bcl-2 over-expressing $\mathrm{T}$ cells and $\mathrm{Lpr} \mathrm{T}$ cells suggests that staurosporine does indeed act by inducing apoptosis through caspases, however this information has to be considered in the light of descriptions of staurosporine inducing apoptosis via mitochondrial caspaseindependent pathways $[27,28]$.

Future in vivo studies are required to validate the enhanced expansion of Bcl-2-derived tumor specific $\mathrm{T}$ cells and to determine if encounter with the relevant tumor antigen will replicate results from chimeric receptor ligation with monoclonal anti-tag antibody. Although the data presented in Fig. (5) suggests that Bcl-2 over-expressing $\mathrm{T}$ cells eventually die, their enhanced persistence may provide sufficient benefit to impact on tumor growth, and repeated 
administration of $\mathrm{T}$ cells would be an option to re-establish tumor-specific $\mathrm{T}$ cell numbers. It would be interesting to investigate $\mathrm{T}$ cell function after it has encountered tumor and testing whether these $\mathrm{T}$ cells can demonstrate "normal" $\mathrm{T}$ cell function after re-encountering antigen. Another issue worthy of investigation is defining how many rounds of receptor ligation these $\mathrm{T}$ cells can undergo while retaining $\mathrm{T}$ cell function. After all, for an increase in life span to improve clinical responses, the lymphocyte must be functional for an extended period.

Our studies have demonstrated 'proof of principle' that over expression of Bcl-2 can improve survival of tumor specific $\mathrm{T}$ cells. This approach was novel as the $\mathrm{T}$ cells were redirected to be specific for the erbB2 antigen. In theory it is possible to extend this approach to many malignancies by altering the specificity of these $\mathrm{T}$ cells. For potential translation of this approach into the clinic, autologous $\mathrm{T}$ cells from patients could be retrovirally transduced with genes encoding both the chimeric $\mathrm{scFv}$ receptor specifically recognizing tumor-associated antigen and $\mathrm{Bcl}-2$ prior to being re-infused back into the patient. This would endow enhanced tumor specificity and increased persistence of transferred T cells. New advances in retroviral design will also enable effective delivery of two transgenes into primary $\mathrm{T}$ cells in the future [29, 30]. A recent study by Charo et al., has shown that adoptive immunotherapy of an established tumor can be significantly enhanced by over expressing Bcl-2 in melanoma-specific $\mathrm{T}$ cell receptor transgenic $\mathrm{T}$ cells [31]. However, in this model increased survival of transduced $\mathrm{T}$ cells in mice was not shown in vivo. Thus, to validate this approach for adoptive immunotherapy, future work would require demonstration that Bcl-2 transduced lymphocytes can survive and persist long term after adoptive transfer, compared with control $\mathrm{T}$ cells.

A potential concern relating to the adoptive transfer of genetically modified cells is the possibility of gene integration to cause oncogene activation leading to transformation of gene-modified $\mathrm{T}$ cells and resulting in leukemia. The development of leukemia in several patients that received retrovirally transduced $\mathrm{CD}_{3}{ }^{+}$stem cells has highlighted the potential risks associated with gene therapy protocols [32]. Nevertheless, reports of cancer arising following transfer of retrovirally gene-modified $\mathrm{T}$ cells in patients have never been observed.

Another concern is whether over expression of Bcl-2 may lead to an enhanced probability of $\mathrm{T}$ cell transformation. However, although expression of Bcl-2 has been implicated in the development of $\mathrm{B}$ cell leukemia, it appears not to play a role in development of $\mathrm{T}$ cell leukemia [33, 34]. Furthermore there has been no reports of $\mathrm{T}$ cell leukemia arising in Bcl-2 transgenic mice [35, 36]. In the study by Charo et al., there were also no reports of cancer arising in long term surviving mice following transfer of Bcl-2 transduced tumor specific lymphocytes and no evidence of malignancy was observed in NOD/SCID mice following transfer of human $\mathrm{T}$ cells gene-modified with another antiapoptotic molecule, Bcl-XL [37]. In any case, if a problem were to arise with the transfer of genetically modified $\mathrm{T}$ cells in patients, treatment with a $b c l-2$ antagonist drug could be used to inhibit $b c l-2$ function [38]. Alternatively, a suicide gene strategy involving hsv-tk (Herpes Simplex Virus thymidine Kinase) [39] or the cytoplasmic domain of Fas could be employed to eliminate rogue cells [40, 41].

Interestingly, $\mathrm{T}$ cell enrichment using nylon wool has recently been described to affect the activation of $\mathrm{T}$ cells, and impact on proliferation and cytokine production [42]. Therefore, although the conclusions of the current study remain valid, since the same enrichment procedure was used throughout, it is not known whether these observations would extend to $\mathrm{T}$ cells generated using other methods.

Apart from over expression of the Bcl-2 gene there are other potential strategies that could be employed to extend the life of tumor-specific lymphocytes. One potential approach involves using small inhibitory RNA's (siRNA) to target pro-apoptotic family members in $\mathrm{T}$ cells [43]. One potential candidate molecule includes Bim [44]. This type of approach warrants further investigation. Another approach with potential to increase persistence of adoptively transferred $\mathrm{T}$ cells involves the modification of virus-specific $\mathrm{T}$ cells that can respond to subsequent virus exposure or immunization [45]. The above mentioned strategies for increasing the persistence of $\mathrm{T}$ cells may need to be combined with the afore mentioned suicide genes to provide a means of controlling the modified $\mathrm{T}$ cells should they become transformed. However, co-expression of several genes in one retroviral vector is still technically challenging and full application of such strategies will require further vector development and optimization. In addition, it is likely that HIVderived vectors will be better vectors for gene transfer into human $\mathrm{T}$ cells and it would be of interest to utilize optimized HIV-derived vectors to determine the potential to extend this approach to human T cells [46].

The above approaches may also be combined with techniques to enhance $\mathrm{T}$ cell trafficking to tumor sites. Techniques such as blocking $\mathrm{T}$ cell adhesion to normal tissues, altering the tumor microenvironment to retain $\mathrm{T}$ cells at the tumor site and delivering $\mathrm{T}$ cells straight to the tumor site have been suggested to improve $\mathrm{T}$ cell trafficking [47]. Importantly, it would be advisable to use constructs and vectors with a low capacity to be immunogenic in vivo, e.g. through omission of foreign selection markers such as the neomycin phosphotransferase gene.

In conclusion, our results have demonstrated that over expression of the Bcl-2 gene can enhance survival of tumor-specific $\mathrm{T}$ cells in vitro, without compromising their specificity or effector function. Thus, these studies suggest that current limitations of persistence and survival of adoptively transferred $\mathrm{T}$ cells may be overcome by expression of the anti-apoptotic gene Bcl-2.

\section{REFERENCES}

[1] Garrido F, Cabrera T, Concha A, Glew S, Ruiz-Cabello F, and Stern PL. Natural history of HLA expression during tumour development. Immunol Today 1993; 14: 491-9.

[2] Gorelik L, Flavell RA. Transforming growth factor-beta in T-cell biology. Nat Rev Immunol 2002; 2: 46-53. 
[3] Haynes NM, Trapani JA, Teng MW, et al. Single-chain antigen recognition receptors that costimulate potent rejection of established experimental tumors. Blood 2002; 100: 3155-63.

[4] Darcy PK, Haynes NM, Snook MB, et al. Redirected perforindependent lysis of colon carcinoma by ex vivo genetically engineered CTL. J Immunol 2000; 164: 3705-12.

[5] Moeller M, Haynes NM, Kershaw MH, et al. Adoptive transfer of gene-engineered CD4+ helper $\mathrm{T}$ cells induces potent primary and secondary tumor rejection. Blood 2005; 106: 2995-3003.

[6] Haynes NM, Trapani JA, Teng MW, et al. Rejection of syngeneic colon carcinoma by CTLs expressing single-chain antibody receptors codelivering CD28 costimulation. J Immunol 2002; 169: 5780-6.

[7] Kershaw MH, Westwood JA, and Hwu P. Dual-specific T cells combine proliferation and antitumor activity. Nat Biotechnol 2002; 20: 1221-7.

[8] Pinthus JH, Waks T, Malina V, et al. Adoptive immunotherapy of prostate cancer bone lesions using redirected effector lymphocytes. J Clin Invest 2004; 114: 1774-81.

[9] Brentjens RJ, Latouche JB, Santos E, et al. Eradication of systemic B-cell tumors by genetically targeted human $\mathrm{T}$ lymphocytes co-stimulated by CD80 and interleukin-15. Nat Med 2003; 9: 27986.

[10] Cheadle EJ, Gilham DE, Thistlethwaite FC, Radford JA, Hawkins RE. Killing of non-Hodgkin lymphoma cells by autologous CD19 engineered T cells. Br J Haematol 2005; 129: 322-32.

[11] Maher J, Brentjens RJ, Gunset G, Riviere I, Sadelain M. Human T-lymphocyte cytotoxicity and proliferation directed by a single chimeric TCRzeta /CD28 receptor. Nat Biotechnol 2002; 20: 70-5.

[12] Kahlon KS, Brown C, Cooper LJ, Raubitschek A, Forman SJ, Jensen MC. Specific recognition and killing of glioblastoma multiforme by interleukin 13-zetakine redirected cytolytic $\mathrm{T}$ cells. Cancer Res 2004; 64: 9160-6.

[13] Hombach A, Schlimper C, Sievers E, et al. A recombinant anticarcinoembryonic antigen immunoreceptor with combined CD3zeta-CD28 signalling targets $\mathrm{T}$ cells from colorectal cancer patients against their tumour cells. Gut 2006; 55: 1156-64.

[14] Westwood JA, Smyth MJ, Teng MW, et al. Adoptive transfer of T cells modified with a humanized chimeric receptor gene inhibits growth of Lewis-Y-expressing tumors in mice. Proc Natl Acad Sci USA 2005; 102: 19051-6.

[15] Dudley ME, Yang JC, Sherry R, et al. Adoptive cell therapy for patients with metastatic melanoma: evaluation of intensive myeloablative chemoradiation preparative regimens. J Clin Oncol 2008; 26: 5233-9

[16] Zhou J, Dudley ME, Rosenberg SA, Robbins PF. Persistence of multiple tumor-specific T-cell clones is associated with complete tumor regression in a melanoma patient receiving adoptive cell transfer therapy. J Immunother 2005; 28: 53-62.

[17] Robbins PF, Dudley ME, Wunderlich J, et al. Cutting edge: persistence of transferred lymphocyte clonotypes correlates with cancer regression in patients receiving cell transfer therapy. J Immunol 2004; 173: 7125-30.

[18] Huang J, Khong HT, Dudley ME, et al. Survival, persistence, and progressive differentiation of adoptively transferred tumor-reactive T cells associated with tumor regression. J Immunother 2005; 28 : 258-67.

[19] Watanabe-Fukunaga R, Brannan CI, Copeland NG, Jenkins NA, Nagata S. Lymphoproliferation disorder in mice explained by defects in Fas antigen that mediates apoptosis. Nature 1992; 356: 314-7.

[20] Ogilvy S, Metcalf D, Print CG, Bath ML, Harris AW, Adams JM. Constitutive Bcl-2 expression throughout the hematopoietic compartment affects multiple lineages and enhances progenitor cell survival. Proc Natl Acad Sci USA 1999; 96: 14943-8.

[21] Morgan RA, Dudley ME, Wunderlich JR, et al. Cancer regression in patients after transfer of genetically engineered lymphocytes. Science 2006; 314: 126-9.

[22] Yee C, Thompson JA, Byrd D, et al. Adoptive T cell therapy using antigen-specific CD8+ T cell clones for the treatment of patients with metastatic melanoma: in vivo persistence, migration, and antitumor effect of transferred T cells. Proc Natl Acad Sci U S A 2002; 99: 16168-73.

[23] Dudley ME, Wunderlich JR, Yang JC, et al. A phase I study of nonmyeloablative chemotherapy and adoptive transfer of autologous tumor antigen-specific $\mathrm{T}$ lymphocytes in patients with metastatic melanoma. J Immunother 2002; 25: 243-51.

[24] Johnson AJ, Smith LL, Zhu J, et al. A novel celecoxib derivative, OSU03012, induces cytotoxicity in primary CLL cells and transformed B-cell lymphoma cell line via a caspase- and Bcl-2independent mechanism. Blood 2005; 105: 2504-9.

[25] Pica F, Franzese O, D'Onofrio C, Bonmassar E, Favalli C, Garaci E. Prostaglandin E2 induces apoptosis in resting immature and mature human lymphocytes: a c-Myc-dependent and Bcl-2independent associated pathway. J Pharmacol Exp Ther 1996; 277 . 1793-800.

[26] Beaty RM, Rulli K, Bost KL, Pantginis J, Lenz J, Levy LS. High levels of IL-4 and IL-10 mRNA and low levels of IL-2, IL-9 and IFN-gamma mRNA in MuLV-induced lymphomas. Virology 1999; 261: 253-62.

[27] Zhang XD, Gillespie SK, Hersey P. Staurosporine induces apoptosis of melanoma by both caspase-dependent and -independent apoptotic pathways. Mol Cancer Ther 2004; 3: 187-97.

[28] Belmokhtar CA, Hillion J, Segal-Bendirdjian E. Staurosporine induces apoptosis through both caspase-dependent and caspaseindependent mechanisms. Oncogene 2001; 20: 3354-62.

[29] Derrington EE, Lopez Lastra MM, Darlix JL. Dicistronic MLVretroviral vectors transduce neural precursors in vivo and coexpress two genes in their differentiated neuronal progeny. Retrovirology 2005; 2: 60-72.

[30] Yu X, Zhan X, D'Costa J, et al. Lentiviral vectors with two independent internal promoters transfer high-level expression of multiple transgenes to human hematopoietic stem-progenitor cells. Mol Ther 2003; 7: 827-38.

[31] Charo J, Finkelstein SE, Grewal N, Restifo NP, Robbins PF, Rosenberg SA. Bcl-2 overexpression enhances tumor-specific T-cell survival. Cancer Res 2005; 65: 2001-8.

[32] Hacein-Bey-Abina S, von Kalle C, Schmidt M, et al. A serious adverse event after successful gene therapy for X-linked severe combined immunodeficiency. N Engl J Med 2003; 348: 255-6.

[33] Baliga BC, Kumar S. Role of Bcl-2 family of proteins in malignancy. Hematol Oncol 2002; 20: 63-74.

[34] Kitada S, Pedersen IM, Schimmer AD, Reed JC. Dysregulation of apoptosis genes in hematopoietic malignancies. Oncogene 2002; 21: $3459-74$

[35] Katsumata M, Siegel RM, Louie DC, et al. Differential effects of Bcl-2 on T and B cells in transgenic mice. Proc Natl Acad Sci USA 1992; 89: 11376-80.

[36] Cory S, Harris AW, Strasser A. Insights from transgenic mice regarding the role of bcl-2 in normal and neoplastic lymphoid cells. Philos Trans R Soc Lond B Biol Sci 1994; 345: 289-95.

[37] Eaton D, Gilham DE, O'Neill A, Hawkins RE. Retroviral transduction of human peripheral blood lymphocytes with $\mathrm{Bcl}-\mathrm{X}(\mathrm{L})$ promotes in vitro lymphocyte survival in pro-apoptotic conditions. Gene Ther 2002; 9: 527-35.

[38] Oltersdorf T, Elmore SW, Shoemaker AR, et al. An inhibitor of Bcl-2 family proteins induces regression of solid tumours. Nature 2005; 435: 677-81.

[39] Cohen JL, Boyer O, Thomas-Vaslin V, Klatzmann D. Suicide gene-mediated modulation of graft-versus-host disease. Leuk Lymphoma 1999; 34: 473-80.

[40] Thomis DC, Marktel S, Bonini C, et al. A Fas-based suicide switch in human $\mathrm{T}$ cells for the treatment of graft-versus-host disease. Blood 2001; 97: 1249-57.

[41] Junker K, Koehl U, Zimmerman S, et al. Kinetics of cell death in T lymphocytes genetically modified with two novel suicide fusion genes. Gene Ther 2003; 10: 1189-97.

[42] Wohler JE, Barnum SR. Nylon wool purification alters the activation of T cells. Mol Immunol 2009; 46: 1007-10.

[43] McManus MT, Haines BB, Dillon CP, et al. Small interfering RNA-mediated gene silencing in T lymphocytes. J Immunol 2002; 169: $5754-60$ 
[44] Bouillet P, Metcalf D, Huang DC, et al. Proapoptotic Bcl-2 relative Bim required for certain apoptotic responses, leukocyte homeostasis, and to preclude autoimmunity. Science 1999; 286: 1735-8.

[45] Pule MA, Savoldo B, Myers GD, et al. Virus-specific T cells engineered to coexpress tumor-specific receptors: persistence and antitumor activity in individuals with neuroblastoma. Nat Med 2008; 14: 1264-70.
[46] Naldini L, Verma IM. Lentiviral vectors. Adv Virus Res 2000; 55: 599-609.

[47] Zhu H, Melder RJ, Baxter LT, Jain RK. Physiologically based kinetic model of effector cell biodistribution in mammals: implications for adoptive immunotherapy. Cancer Res 1996; 56: 3771-81.

Received: February 9, 2009

Revised: April 7, 2009

Accepted: April 7, 2009

(C) Pegram et al.; Licensee Bentham Open.

This is an open access article licensed under the terms of the Creative Commons Attribution Non-Commercial License (http://creativecommons.org/licenses/by-nc/3.0/) which permits unrestricted, non-commercial use, distribution and reproduction in any medium, provided the work is properly cited. 